\title{
Multi-Cycle Statistical Analysis of Laboratory Salt Weathering Tests ${ }^{\dagger}$
}

\author{
Carlos Alves ${ }^{1, *}$ and Carlos Figueiredo ${ }^{2}$ \\ 1 LandS/Lab2PT (Landscape, Heritage and Territory Laboratory), UID/AUR/04509/2013, \\ POCI-01-0145-FEDER-007528, and Earth Sciences Department, School of Sciences, University of Minho, \\ 4710-057 Braga, Portugal \\ 2 CERENA-Centro de Recursos Naturais e Ambiente, UID/ECI/04028/2013, DEcivil, Instituto Superior \\ Técnico, University of Lisbon, 1049-001 Lisbon, Portugal; carlos.m.figueiredo@ist.utl.pt \\ * Correspondence: casaix@dct.uminho.pt; Tel.: +00351253604300 \\ † Presented at the 1st International Electronic Conference on Geosciences (IECG 2018), 15-30 June 2018; \\ Available online: https://sciforum.net/conference/IECG_2018.
}

Published: 13 June 2018

\begin{abstract}
Soluble salts are an important pollutant and the main decay agent of stone in the built environment. While their end erosive effects are well-established, the evolution in time of those erosive effects has been much less studied. This paper presents multivariate analyses of results from salt weathering cycles of three limestone types.
\end{abstract}

Keywords: weathering; temporal evolution; petrologic modeling of geologic materials

\section{Introduction}

Soluble salts are important pollutants in the built environment (having both anthropogenic and geogenic sources), and salt weathering is the most widespread erosive hazard for stone materials in cultural heritage (it also affects some contemporaneous stone works). While end-term erosive effects are well-established, their evolution in time has been much less studied. This temporal aspect is, nonetheless, often very important from an applied perspective when it is necessary to assess whether a given observed decay situation is at equilibrium or will evolve in the sense of further erosion (hence requiring interventions to avoid that kind of evolution).

Laboratory tests for assessing the effect of salt weathering are generally based on final mass variation after a certain number of cycles simulating salt effects (as is indicated in the European Standard EN 12370 based on cycles of immersion in sodium sulphate solutions followed by oven drying). Most of the studies with these tests consider the final mass loss or the curve of total mass variation (which represents a cumulative representation). Angeli et al. [1] proposed a general pattern for the curve of mass variation along cycles in these kinds of salt weathering tests: an initial mass increasing phase (related to salt accumulation) that might be followed or not by a phase of mass increase or decrease (according to the balance between salt accumulation and specimen erosion) and, finally, a clear mass decreasing phase. These authors also propose to consider the cycle during which the first damage occurred (alteration index), as well as the final value of the derivative of the mass variation curve (alteration velocity). Alves et al. [2] assessed the use of diverse parameters related to the initial mass increasing phase (mass increase after first cycle and maximum mass increase), relating them also to the volume of absorbed salt solution, as well as parameters related to the mass decrease phase (maximum mass differential and median mass differential, expressed as percentage of the initial mass). However, we were unable to find any previous study that considered the whole set of results obtained in the different cycles in multivariate analyses, as we pretend to do 
here. These analyses will be discussed in the concrete context of three limestone types, and it will be shown that this study can lend further quantitative and reproducible support and corroboration to the petrological models that have been proposed to explain the behaviour of rock types under salt pollution conditions, contributing hence to further our research in petrological modeling of salt weathering.

\section{Materials and Methods}

This study is based on the results of salt weathering laboratory tests on three Portuguese limestone types: two grainstones (Semi-rijo and Moca Creme) and a travertine. These rock types are detailed described in Alves et al. [3], but it will be useful to mention here that the grainstones have diverse allochemical components with a sparry cement (being the allochemical components coarser in Moca Creme than in the Semi-rijo), and the travertine (presents) is dominated by compact portions but presents diverse more friable (detritic-rich) portions with an irregular distribution (at the specimen scale). Salt weathering tests were performed on cubic specimens of these rock types following the indications of the European Standard (EN 12370) by 15 cycles of immersion in sodium sulphate solutions and oven-drying, being the final mass measured after thorough washing of the specimens. These salt weathering tests showed [3] higher mass losses in the grainstones than in the travertine (higher in Moca than in Semi-rijo). The study of Alves et al. [2] showed that the parameters (presented above in the introduction) related to the mass increase phase and mass decrease phase separated the travertine from the grainstones, and the parameters of the mass decrease phase present a good correlation with the final mass loss value (unlike the results of the mass increase phase). It will also relevant to refer for these rock types what Angeli et al. [1] refer as weathering patterns. The grainstone specimens present a homogeneous weathering pattern (in the sense of [1]), with rounding of edges and corners (which are generally similar among the different specimens), while travertine presented a heterogeneous weathering pattern (in the sense of [1]), with marked differences in different zones of the same specimen with an irregular distribution.

In this study, the mass differential between successive cycles as a percentage of initial mass will be considered. The results of the different cycles will be represented in a matrix plot (allowing the presentation of coloured areas of the results of the differences between successive cycles for each specimen and cycle) and submitted to cluster analyses (both K-means and hierarchical analyses; basics of these techniques can be found in [4]) and Principal Component Analysis (PCA; see [4] for details), as well as multivariate statistical tests for comparison of groups (one-way ANOSIM and one-way PERMANOVA; see [5] for details of these tests) with $10^{7}$ permutations to ensure higher stability of results. Page's test (see details in [6]) is not strictly a multivariate test, but its results are also based on diverse measurements on the same subject (specimens in this case). Page's test was applied considering the last ten cycles to assess whether there is a trend towards increasing mass loss between cycles. Euclidean distances were used in all distance assessments (cluster hierarchical analyses, one-way ANOSIM, and one-way PERMANOVA). Standardized values (obtaining by subtracting the mean and dividing by the standard deviation) were used in cluster analyses, PCA, and multivariate tests to avoid the undue effect of differences in variance of the considered variables (cycles). In the hierarchical cluster analyses, the following available classification procedures were used: single linkage, complete linkage, unweighted pair-group average, weighted pair-group average, unweighted pair-group centroid, weighted pair-group centroid (median), and Ward's method (details of these different classification procedures can be found in [4]). All cluster and principal component analyses were performed in Statistica 11 (Statsoft). Statistical multivariate tests (one-way ANOSIM and one-way PERMANOVA), as well as the boxplot related to one-way ANOSIM, were obtained with the freeware PAST [7], with the boxplot being graphically treated with the drawing module of the open freeware LibreOffice.

\section{Results and Discussion}

In Figure 1, a matrix plot is presented with the differences between successive plots (normalized by initial mass) for all the specimens and cycles studied. This kind of plot allows one to 
see that the variations are more marked in the Semi-rijo and Moca Creme specimens, both at the beginning (positive variations) and end (negative variations) of the salt crystallization tests, especially at the end of the Moca Creme tests. One can also see that in the grainstone specimens, there is a certain up and down irregularity in the intermediate portions of the tests (it will be relevant to highlight that this pattern will be much harder to detect with the more usual cumulative curve of mass variation). Diverse statistical tools can help one to assess this visual analysis.

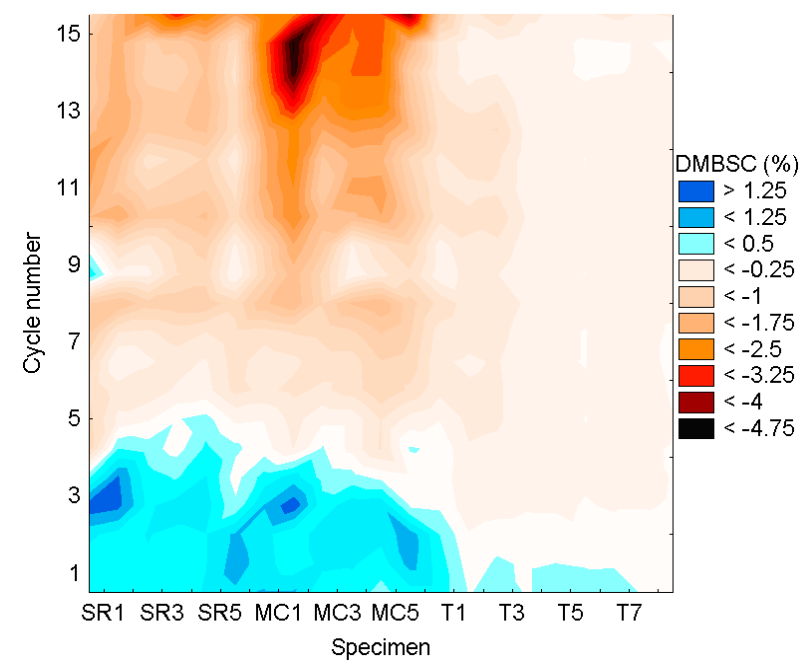

Figure 1. Matrix plot of mass difference between successive cycles in $\%$ of initial mass for specimens of the two grainstone types (Semi-rijo, SR, and Moca Creme, MC) and travertine (T).

Cluster K-means analysis (Table 1) for a three clusters model shows all travertine specimens in one cluster and a mix of the grainstone specimens in the other two. If 2 clusters are proposed instead, all the grainstones are placed in one cluster and all the travertine specimens in the other (distance values also show the distinction of the travertine specimens in relation to the grainstones).

Table 1. K-means cluster analyses of the specimens of the two grainstone types (Semi-rijo, SR, and Moca Creme, $\mathrm{MC}$ ) and travertine (T) with distribution by clusters and distance for 3-clusters and 2-cluster models.

\begin{tabular}{cccccc}
\hline 3-Clusters & Specimen & Distance & 2-Cluster & Specimen & Distance \\
\hline Cluster 1 & SR1 & 0.77 & Cluster 1 & SR1 & 0.75 \\
& MC1 & 0.89 & & SR2 & 0.90 \\
& MC2 & 0.51 & & SR3 & 0.68 \\
& MC4 & 0.78 & & SR4 & 0.93 \\
& MC5 & 0.72 & & SR5 & 0.71 \\
Cluster 2 & SR2 & 0.79 & & SR6 & 0.54 \\
& SR3 & 0.53 & & MC1 & 1.10 \\
& SR4 & 0.83 & & MC2 & 0.89 \\
& SR5 & 0.36 & & MC3 & 0.58 \\
& SR6 & 0.40 & & MC4 & 1.20 \\
& MC3 & 0.52 & & MC5 & 0.74 \\
& MC6 & 0.44 & & MC6 & 0.60 \\
Cluster 3 & T1 & 0.12 & Cluster 2 & T1 & 0.12 \\
& T2 & 0.69 & & T2 & 0.69 \\
& T3 & 0.11 & & T3 & 0.11 \\
& T4 & 0.09 & & T4 & 0.09 \\
& T5 & 0.24 & & T5 & 0.24 \\
& T6 & 0.21 & & T6 & 0.21 \\
& T7 & 0.17 & & T7 & 0.17 \\
& T8 & 0.19 & & T8 & 0.19 \\
\hline
\end{tabular}


All the hierarchical cluster analyses put all travertine specimens in a cluster separated from the grainstones, albeit single linkage puts one Moca Creme specimen nearer the travertine than the other grainstone specimens. In Figure 2, are presented two plots that exemplify the results of hierarchical cluster analyses (single linkage, Figure 2a, and Ward's method, Figure 2b).

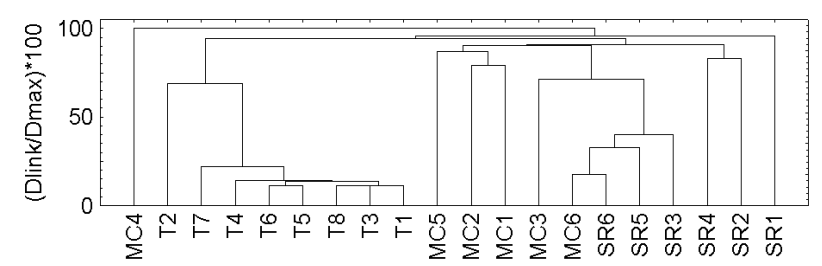

(a)

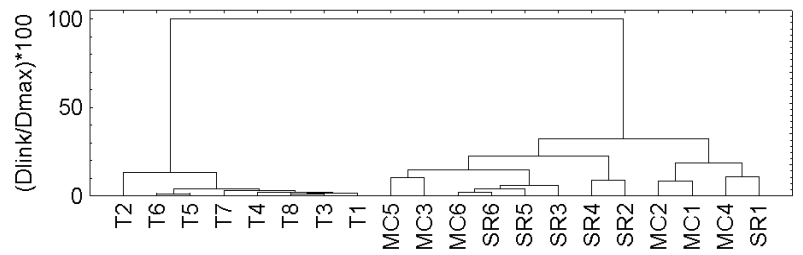

(b)

Figure 2. Dendrograms from hierarchical cluster analyses based on Euclidean distance measures for specimens of the two grainstone types (Semi-rijo, SR, and Moca Creme, MC) and travertine (T): (a) single linkage and (b) Ward's method.

The observation of PCA plots can help further the discussion of these results. Figure 3a presents the PC2-PC1 plot of the specimens showing that travertine specimens are separated from the grainstones by $\mathrm{PC} 1$, with $\mathrm{T} 2$ being almost in an intermediate position between the plotting of the other travertine specimens and the plotting of the grainstones. One can also highlight that the dispersion in terms of PC1 is much higher for the Moca Creme specimens than for Semi-rijo and travertine specimens. In terms of PC2, the dispersion is clearly higher for the grainstones than for the travertine specimens. The plot of the variables (Figure 3b) shows that PC1 has a strong positive association with the initial cycles and a strong negative association with the final cycles. PC2 is related to most of the intermediate cycles. Hence, PC2 could be related to the phase referred by Angeli et al. [1] as corresponding to a balance between mass gain and the beginning of the erosive breakdown.

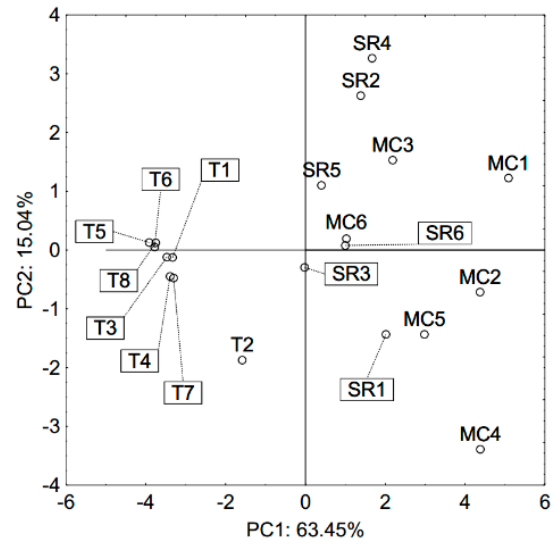

(a)

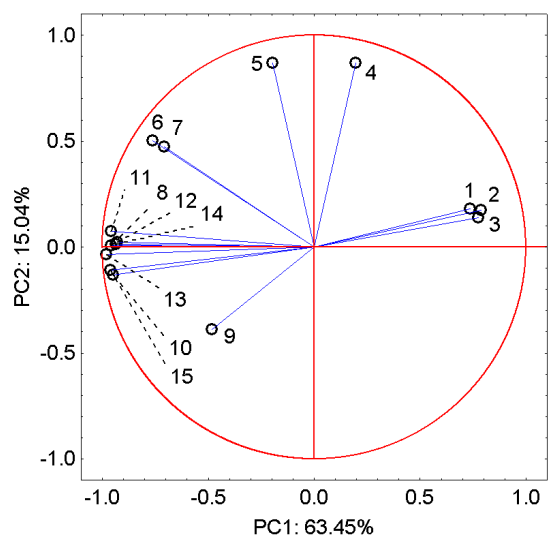

(b)

Figure 3. Plot of PC2 against PC1 for specimens of the two grainstone types (Semi-rijo, SR, and Moca Creme, MC) and travertine (T): (a) specimens and (b) variables.

One-way ANOSIM and one-way PERMANOVA tests (Table 2) in the comparison of the three previously defined groups converge, indicating a very low p-value for the null hypothesis of all the groups being the same. In the two-way comparisons between the groups, $p$-values are two orders of 
magnitude lower for the comparison between the grainstone types and the travertine than for the comparison between the two grainstone types (Semi-rijo and Moca Creme). The boxplot of ranked distances (Figure 4) for the results of the ANOSIM analysis shows higher results for the grainstones than for the travertine specimens (with Moca Creme specimens presenting higher ranked distances than Semi-rijo).

Table 2. Results of one-way ANOSIM and one-way PERMANOVA multivariate tests $\left(10^{\wedge} 7\right.$ permutations) on specimens of the two grainstone types (Semi-rijo, SR, and Moca Creme, MC) and travertine $(\mathrm{T})$.

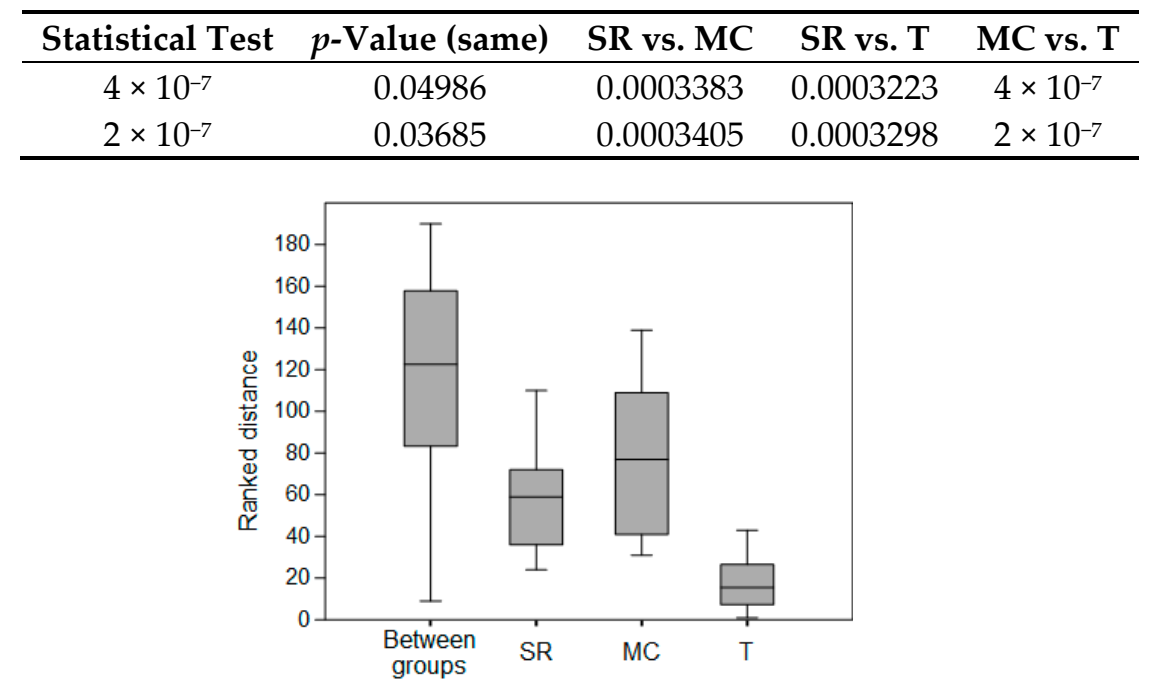

Figure 4. Boxplot of ranked distance obtained in the ANOSIM test between groups and for the groups considered corresponding to the two grainstone types (Semi-rijo, SR, and Moca Creme, MC) and travertine $(\mathrm{T})$.

For the grainstone, the results of Page's L statistic (2144 for Semi-rijo and 2237 for Moca Creme) are above the critical value (indicated in [6]) for 6 subjects, 10 measurements and $p=0.001$ (meaning $p$-value $<0.001$ ) while for the travertine the $L$ statistic $(2424)$ is below the critical value for 8 subjects, 10 measurements and $p=0.05$ (meaning $p$-value $>0.05$ ). If the grainstones are considered together, the $L$ statistic will be 4381 , which is above the critical value for 12 subjects, 10 measurements and $p=$ 0.001 (meaning $p$-value $<0.001$ ).

\section{Conclusions}

The detailed analysis of the results of mass differences between successive cycles of salt weathering laboratory tests clearly separates the travertine from the grainstones. The usefulness of this tool is largely proved and underpinned by the generally convergent results obtained by applying the panoply of multivariate analysis procedures that were tried in this study as an alternative perspective to more traditional analyses based on the final mass loss; they could help one to discuss the behaviour in time of the stones under salt weathering. The petrographical model of salt weathering can help one to understand the different behaviour of these rock types under salt weathering conditions. While in the travertine specimens, salt weathering will be limited to the more susceptible zones of the specimens (given the heterogeneous character of this rock), in the grainstones salt weathering proceeds through the development of fissures along the edges of the specimens, and further cycles seem to promote further fissures. After the initial cycles and due to higher erosion, the results from the Moca Creme begin to diverge from those of the Semi-rijo given the coarser textural heterogeneities in this rock type. The presence of coarser grains will imply a higher mass loss in Moca Creme and possibly fissures that penetrate deeper (given that the interface grains/cement is deeper on account of coarser grains), but the behaviour over time will be essentially similar. In a lay terms synthesis, one could say that the grainstones are being "peeled off" along the 
successive cycles (Moca Creme with coarser layers). In the travertine, the erosive process goes on "nibbling" the more susceptible zones (the ones that are more affected by the salt weathering and that our previous studies suggest are the detritic enriched portions), while salt penetration is limited by the contrast with the more compact portions.

The results of this study of cycles could be considered relevant for the understanding of the behaviour of stones in the field over time. They suggest that, if salt weathering cycles persist, mass loss does not stop after the onset of erosion, and, in some cases (as in the grainstones), mass loss could increase over time, even after the erosion of significant portions of the specimens.

Author Contributions: Both authors contribute to the preparation of this publication.

Funding: The experimental data considered in this publication discussed were obtained in the context of the Project PORENET (POCTI/CTA/44940/2002) funded by the FCT-Fundação para a Ciência e Tecnologia (Portugal). The software and informatic equipment used in the preparation of this publication were also supported from funding of the FCT to the Centro de Investigação Geológica, Ordenamento e Valorização de Recursos of the School of Sciences of the University of Minho.

Acknowledgments: The Lab2PT, Landscape, Heritage, and Territory Laboratory(UID/ECI/04028/2013) of the University of Minho and the CERENA-Centro de Recursos Naturais e Ambiente (UID/ECI/04028/2013) of the Instituto Superior Técnico, University of Lisbon are supported by the FCT-Fundação para a Ciência e Tecnologia (Portugal), with Portuguese funds and funds from the European Union (FEDER, Programa Operacional Factores de Competitividade-COMPETE 2020-Programa Operacional Competitividade e Internacionalização, POCI, POCI-01-0145-FEDER-007528). Acknowledgments also to Eng. Teresa Luís, Eng. Sónia Pereira, and Enterprise Mármores Galrão for the rock blocks.

Conflicts of Interest: The authors declare no conflict of interest.

\section{References}

1. Angeli, M.; Bigas, J.-P.; Benavente, D.; Menéndez, B.; Hébert, R.; David, C. Salt crystallization in pores: Quantification and estimation of damage. Environ. Geol. 2007, 52, 205-213, doi:10.1007/s00254-006-0474-z.

2. Alves, C.; Figueiredo, C.; Maurício, A. A Study of Salt Weathering Cycles Impact on Limestones. Procedia Earth Planet. Sci. 2017, 17, 316-319, doi:10.1016/j.proeps.2016.12.070.

3. Alves, C.; Figueiredo, C.; Maurício, A.; Braga, M.A.S.; Aires-Barros, L. Limestones under salt decay tests: Assessment of pore network-dependent durability predictors. Environ. Earth Sci. 2011, 63, 1511-1527, doi:10.1007/s12665-011-0915-1.

4. Dunn, G.; Everitt, B.S. An Introduction to Mathematical Taxonomy; Dover Publications: Mineola, NY, USA, 2004; ISBN 9780486151366.

5. Hammer, Ø. PAST PAleontological STatisticsVersion 3.20 Reference Manual. Available online: https://folk.uio.no/ohammer/past/past3manual.pdf (accessed on 24 May 2018).

6. Siegel, S.; Castellan, N.J. Nonparametric Statistics for the Behavioral Sciences; McGraw-Hill international Series; McGraw-Hill Book Comp.: New York, NY, USA, 2002; ISBN 978-0-07-100326-1.

7. Hammer, Ø.; Harper, D.A.T.; Ryan, P.D. PAST: Paleontological statistics software package for education and data analysis. Palaeontologia Electronica 2001, 4, 1-9.

(C) 2018 by the authors. Licensee MDPI, Basel, Switzerland. This article is an open access article distributed under the terms and conditions of the Creative Commons Attribution (CC BY) license. 